
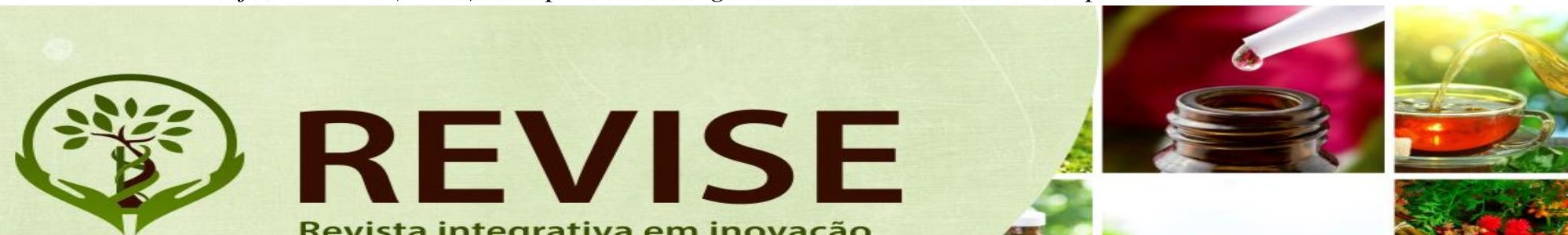

Revista integrativa em inovação tecnológica nas ciências da saúde

ISSN: $2179-6572$

\title{
Conferência: EXPERIÊNCIAS DE PRÁTICAS INTEGRATIVAS DA SANTA CASA DE MISERICÓRDIA DE CACHOEIRA DA BAHIA.
}

\author{
Luiz Antônio Costa Araújo \\ Hospital Santa Casa de Misericórdia
}

\begin{abstract}
RESUMO
O artigo registra as conferências do congresso internacional de inovação tecnológica nas ciências da saúde: a sustentabilidade das práticas integrativas a agroecologia, mais especificamente a conferência Experiências De Práticas Integrativas Da Santa Casa De Misericórdia de Cachoeira/Bahia. A conferência apontou os caminhos para a residência médica multiprofissional, devido as experiências multiprofissionais com conhecimentos tradicionais da medicina da religião de matrizes afrodescendentes na Santa Casa de Misericórdia do município de Cachoeira/Bahia/Brasil. O evento aconteceu de 15 a 18 de novembro de 2017 no IFBA SAJ sob a direção da Universidade Federal do Recôncavo da Bahia.

Palavras-chave: Residência Multiprofissional. Práticas Médicas. PICS.
\end{abstract}

\begin{abstract}
The article records the conferences of the international congress on technological innovation in health sciences: the sustainability of integrative practices and agroecology, specifically the conference Experiences of Integrative Practices of the Santa Casa de Misericordia of Cachoeira / Bahia. The conference pointed the way to multiprofessional residency, due to multiprofessional experiences with traditional knowledge of religion medicine of African descent mothers in the Santa Casa de Misericordia of Cachoeira / Bahia / Brazil. The event took place from November 15 to 18, 2017 at IFBA SAJ under the direction of the Federal University of Recôncavo da Bahia.

Keywords: Multiprofessional Residence. Medical practices. PICS.
\end{abstract}



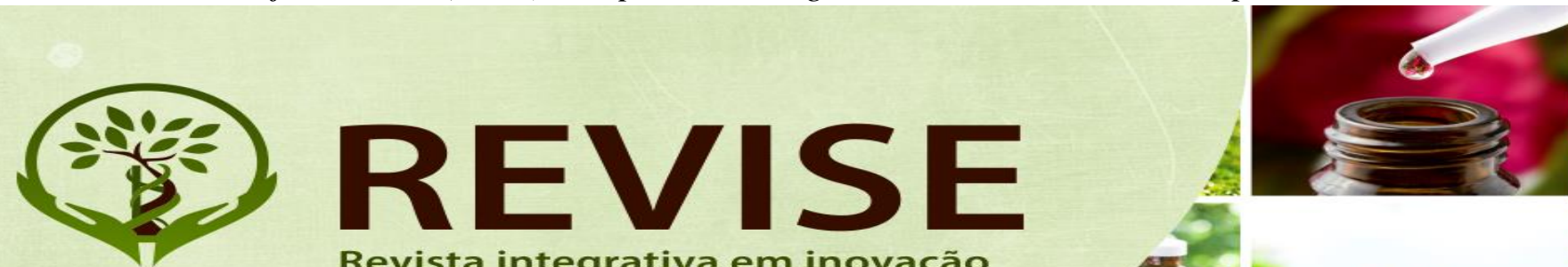

Revista integrativa em inovação tecnológica nas ciências da saúde

ISSN: $2179-6572$

Da negação dos negros e negras no Brasil.

"Eu quero aqui agradecer a oportunidade ao convite a toda comissão organizadora do congresso. Foi muito interessante ter chegado nesse congresso após uma visita muito bacana, de um grupo de doutores em ciências da saúde da UFRB, lá nas instalações do hospital são João de Deus, a Santa Casa de Misericórdia de Cachoeira - Bahia/Brasil. Então eu acho que nós estamos lá no hospital Santa Casa, com uma disposição extraordinária. Ontem demos um passo extraordinário muito bom porque a diretora do Centro, a professora Flávia esteve presente com o Reitor Silvio, com o diretor do Centro de Artes Humanidades e Letras - CAHL/UFRB, exatamente para fazermos essa sinfonia institucional. como na música, pondo essa viola, esses tambores, para virar uma orquestra.

Nós estamos com a possibilidade de restaurar uma parte da história do Brasil em vários aspectos. Porque tudo é transversal, tudo é holístico, mas a ciência dominante ela trabalha para que a gente não pense holisticamente, a gente pense a saúde como a medicação, como o internamento hospitalar; e o médico como salvador de vida; aí a gente abandona todo o conhecimento, todo um saber da ancestralidade, que é a ciência natural, que é a ciência tradicional, que dá o suporte para os cientistas formalizar isso, patentear, e industrializar, e ir para o mercado com uma prática de transformar nós seres humanos como a mercadoria. Então não é fácil, porque estamos vivenciando uma responsabilidade de estar gerindo uma instituição hospitalar que nessa lógica do capital, funciona como uma prateleira de mercadorias que é o corpo humano; e vender os produtos da indústria farmoquímica; os médicos ganha dinheiro com essa mercadoria, ao manipular o corpo humano como mercadoria, ao pensar no ser humano como mercadoria; manipular essa mercadoria que somos nós, é um exercício de dominação poderosíssimo e sutil. O Foucault (1979) no livro “A Microfísica do Poder “dá as dicas 

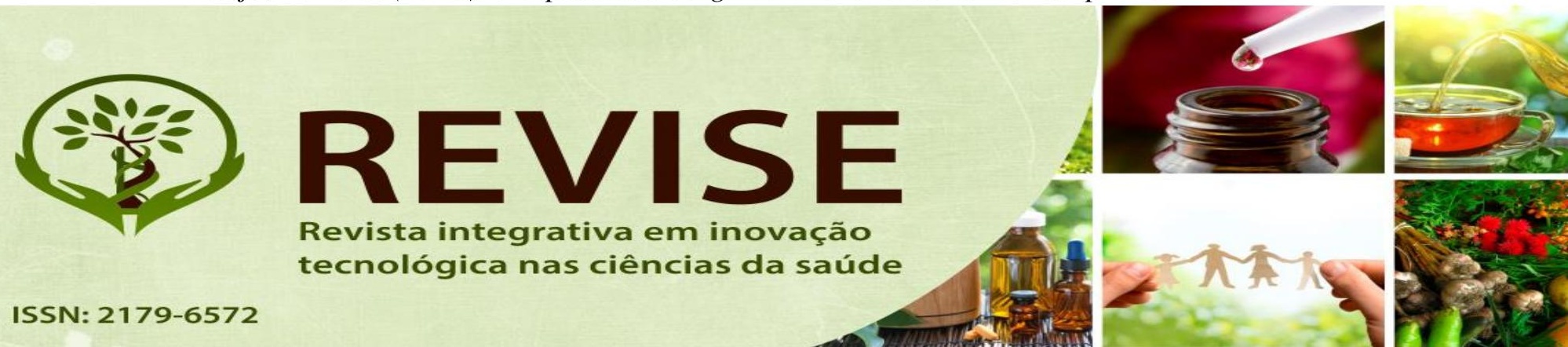

ISSN: $2179-6572$

Revista integrativa em inovação tecnológica nas ciências da saúde

para gente compreender esse processo. E aí termina se negando todos outros recursos de uma sabedoria da medicina tradicional. As ações da medicina contribuem para tocar num atendimento mais completo, mais integral do corpo humano. $\mathrm{Na}$ visita que a turma teve lá, os doutores da UFRB com seus dirigentes nós tivemos a oportunidade de revelar algumas coisas interessantíssimas que nós gerenciamos, fazemos a gestão. E logo aonde? Em Cachoeira, a cidade histórica que girou o comércio maior de escravos no interior da Bahia, devido as grandes as compras de fazendas de engenho. Em Cachoeira algumas vidas humanas, com o seu grau de enfermidade, vão ao hospital para o seu atendimento de urgência e emergência, na estabilização da tontura, a pressão arterial alta. Vem um diagnóstico mais preciso do que nós somos acometidos muitas vezes por uma dieta, por abusos, nossos mesmos. A gente torna-se um cardiopata, um diabético, tornamos uma vítima de um distúrbio gastro intestinal. E todo dia a gente vai comprar remédio e vai ser internado para estabilizar. E, às vezes, a gente negligencia.

É interessante a gente viver práticas integrativas assim riquíssimas, sutis que precisa ser discutido na academia. Na cidade de Cachoeira - Bahia as pessoas têm uma relação com a religiosidade de matriz africana do candomblé; lá nas suas conturbações de saúde, recorrem-se ao médico, ao babalorixá, ao orixá. E entra no processo terapêutico, o chá, a raiz, o tipo de gênero alimentício que é recomendado. Isso é uma prática muito comum nos terreiros e que lá na ponta o exercício, da terapia da medicina tradicional está sendo feito pela sabedoria dessas autoridades. E lá nós temos no hospital, um conjunto de técnicas de enfermagens. E é interessante é que são mais as mulheres mesmo que são da religiosidade do candomblé, que tomaram o curso de técnica de enfermagem aprenderam a injeção, medir a pressão, que tem toda uma sabedoria armazenada que é a sua força mediúnica do seu orixá. Então, por exemplo, por vezes eu testemunhei na madrugada, um fato muito gritante: uma adolescente de 16 anos chegou para um parto, com registros anteriores no hospital como usuária de crack. Então imagina que a adolescente ao fazer o contato com a gente comunitária de saúde 

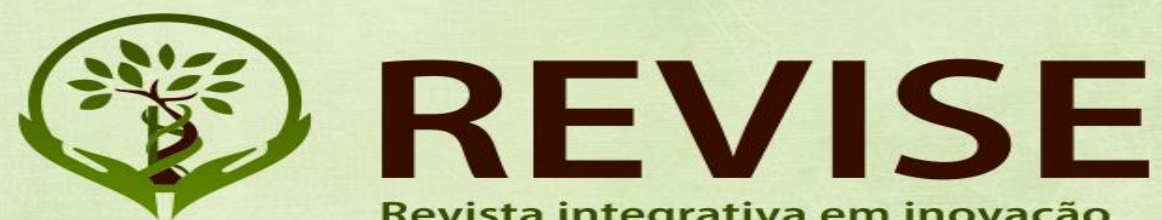

Revista integrativa em inovação tecnológica nas ciências da saúde

ISSN: $2179-6572$

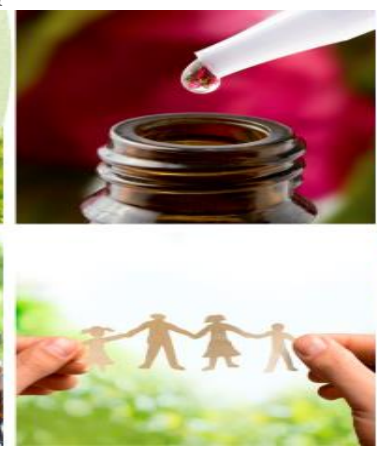

tinha dificuldade de realizar o exame preventivo; então a ficha dela já não atendia ao preventivo etc.

Chegou na hora de fazer o parto e nesse momento que estava se manipulando o corpo para a saída da criança o Exu, entidade das religiões de matrizes africanas que liga o humano ao mundo dos orixás, chegou e disse que não ia sair ninguém. E teve que mobilizar vários homens porque as meninas [as enfermeiras] que estavam lá, as mãe pretas, que tavam lá não tavam conseguindo fazer os exercícios; porque a contração da perna era forte: então foi médico, foi todo mundo, e todo mundo saiu correndo, porque o Exú tava brabo: "Eu vou lhe levar! Eu lhe levo!" E estava manifestado de uma maneira muito contundente! Consequentemente o plantão era do Doutor Manuel, que é médico espírita kardecista e quando ele chegou que observou ele disse: Bom, é uma entidade. E todo mundo pegando abrindo as pernas, e segura e controla, uma técnica de enfermagem do terreiro ela se afastou fechou os olhos e convocou sua entidade, ela chegou e começou a estabelecer o diálogo da técnica de enfermagem, com o Exú. E Exu teve que ir embora. E uma contribuição do doutor Manoel, que ao se afastar fechou os olhos, e nesse momento, a criança nasceu. Então não é a primeira vez; essa eu testemunhei, eu vi. não dá para dizer: vá buscar o celular.

E aí há uma sequência de terapias que nós estamos habituados a vivenciar no hospital e administrar. Tipo uma vez também forte, um paciente já no quadro terminal nos diagnósticos de exame. E, filho de santo do terreiro de Justo... : Nesse momento nós temos que ter o cuidado, quer dizer, o serviço social deve ser feito por todos nós. Então a gente se aproxima para saber qual é o histórico de vida daquelas pessoas, e veio o histórico de vida de uma total desobediência a toda sua ritualística que foi recomendada na religiosidade do candomblé. E ali estava um desastre. E mandaram avisar: "Você desobedeceu tudo, e vá embora! O que vai restar agora é uma celebração ritualística para lhe conduzir da melhor maneira." Mas nessa hora, a pressão familiar de amigos é grande em cima daquele mestre, daquele doutor, daquela doutora que está ali. Já deu o diagnóstico de lá. E o médico com o diagnóstico de todo exame: alto grau de 

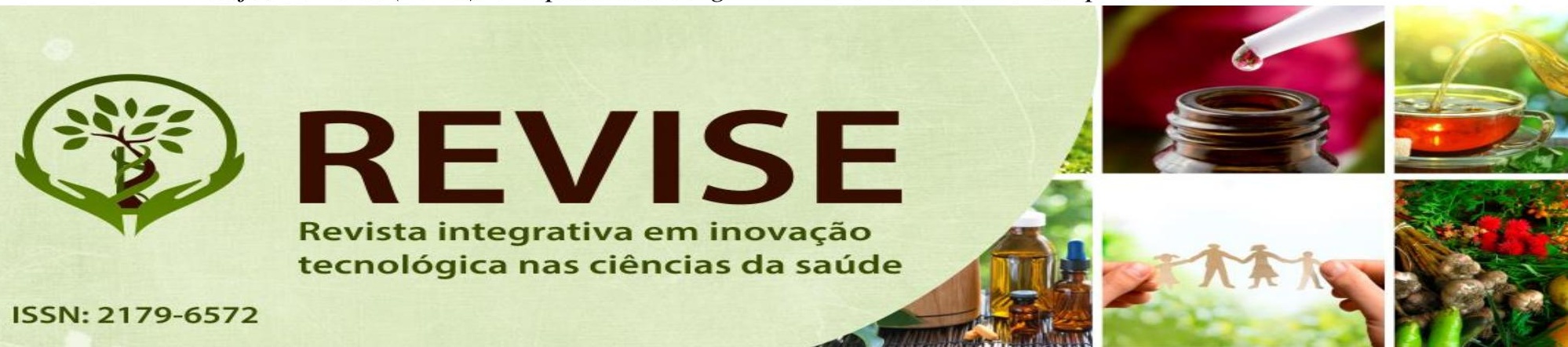

ISSN: 2179-6572

Revista integrativa em inovação tecnológica nas ciências da saúde

infecção. Então não tinha mais jeito. Então, pediram para fazer o último ritual e abriu uma discussão: como fazer um ritual? Um trabalho dentro do hospital? Imagina o conflito, né? Normas, rotinas e todo o protocolo de um hospital contra infecção hospitalar: o que que toma, o que entra no leito, quem entra no leito, como entra a bactéria já era daquela mais braba. Nesse momento entra para a gente administrar, e já estava um movimento para uma ação clandestina: Como é que a gente entra no leito para fazer?

Então, a gente fica muito atento como fazer, então vamos negociar como fazer: "não é uma despedida, a gente sabe que não tem mais jeito" sim, então vamos conversar esta despedida. Aí entra uma gestão hospitalar com essa compreensão holística: vamos conversar, para conversar tem que entender dessa outra ciência, né? Então consulta-se os mais velhos. E a gente tem que sentar-se com quem está preparando aquela terapia para saber os detalhes dela, as consequências dela. Era quase uma troca de cabeça dentro de um hospital. Um problema, né? Então ao consultei o mais velho, exigi qual era o detalhe o que seria utilizado. Ao ser consultado o mais velho me disse: "Esse povo que está querendo fazer isso é louco! Pode segurar essa vida, mas vai todo mundo que está próximo: quem estiver fragilizado vai receber a bomba. Não deixe fazer, por isso, isso e isso." Então, a gente vai nessa consulta e vem dialogar com quem estava querendo fazer aquela ação e aí a gente tem que dizer que o mais velho revelou que é incorreto e as consequências são essas. Foi admitido que ele estava certo, foi desfeito. E eu voltei a consultar o doutor mais velho: "O que era possível fazer dentro da intenção, de um quadro diagnóstico, naquela situação?" "Pode fazer isso, isso e isso; porque não usa a carne, não usa o sangue, então pode fazer; não tem problema." Então a gente negocia esse conhecimento, essas terapias: "Pode fazer".... então a gente prepara e veja como a complexidade de tratar isso; porque tem a enfermeira, o médico, o paciente, que é evangélico, principalmente o evangélico; porque o católico ele tem um pé em um e no outro, já o evangélico radicaliza. "O demônio", então você tem que fazer essa administração. Eu estou dando exemplo dos procedimentos, porque quando eu estava no 

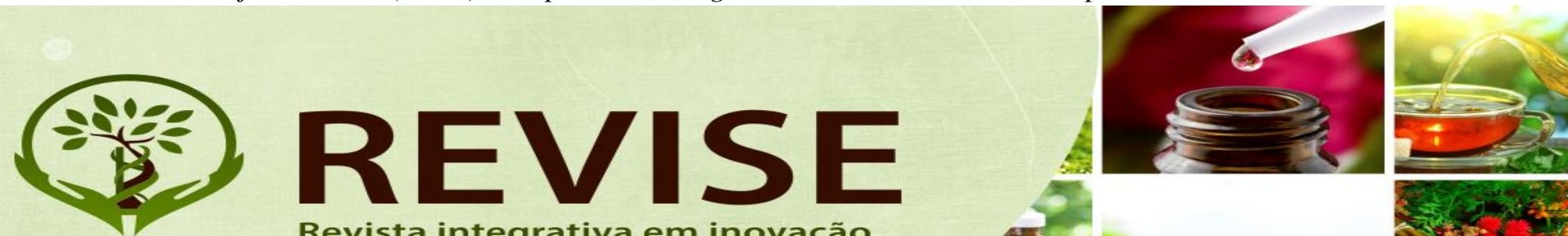

Revista integrativa em inovação tecnológica nas ciências da saúde

ISSN: $2179-6572$

debate dessa natureza a gente encontra vários materiais bibliográficos que legitimam práticas da medicina tradicional, e a china é uma referência que legitima todo mundo né?

Então o Brasil, inclusive teve contribuições de profissionais da medicina, de médicos, autoridades já reconhecidas na Organização Mundial de Saúde - OMS/ONU que ajudou o Brasil em 2005 a aprovar uma portaria ministerial onde legitima, de maneira legal, as práticas da medicina tradicional e complementar no sistema Único de Saúde - SUS. Que ganho extraordinário! E a imprensa, você não viu em uma novela, em um comentário! Mas isso foi um avanço profundo que o governo popular, um governo de esquerda, o Lula, o seu pensamento que estava em torno dele, avançou com a política pública. E isso abre as portas para exatamente esse Centro de Ciências da Saúde. Por isso numa discussão como se discute a maioria dos jovens que entram no curso de medicina já dizendo assim: "Que dia eu faço a especialização em ultrassonografia?" Então o chamariz para entrar em um curso superior, na área de saúde, seja qual for. Você fica sonhando com aquela autoridade transitando com uma lógica que é perversa, porque essa é outra revelação que nós que estamos dentro do hospital vivenciamos; a por exemplo eu até hoje ouço: "Você defende um governo que vai destruir com a nossa própria profissão?" Eu digo: Porque doutor? "Inventando curso de Medicina no recôncavo? na UFRB? daqui a uns dias nós vamos virar médicos como advogados de porta de cadeia que em cada esquina tem um advogado." Eu digo: Que ótimo, que ótimo que tivesse em cada esquina um médico, uma médica! Que ótimo! A lógica do mercado mudava, a oferta e procura da mão de obra mudava, a consciência profissional mudava, e a compreensão sobre a atenção a saúde iria ser como Cuba é. Quantos médicos, quantas médicas, quantos engenheiros, dividindo táxis, jogando futebol e box, em várias atividades da divisão de social do trabalho, para manter-se por dignidade?

Então isso, essa abordagem da prática da Medicina Tradicional Complementar, é uma coisa muito profunda: muda as relações de poder! Literalmente muda as relações de poder! Então, por tanto, eu quero concluir aqui o meu tempo, e colocar a 

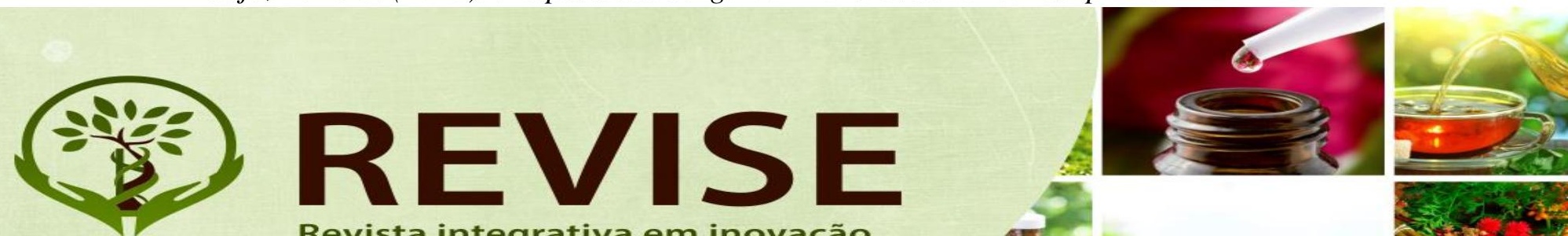

Revista integrativa em inovação tecnológica nas ciências da saúde

ISSN: $2179-6572$

interrogação: é lei ministerial! Que desafio grande ter o Centro de Ciências da Saúde! Que desafio grande ter nós, que estamos dentro uma instituição hospitalar, e declarando para vocês, UFRB e mundo que nós estamos próximo e vamos dar as mãos em parceiras, em convênios! E começamos a tratativa para nos tornamos um hospital de ensino, e de residência médica multidisciplinar! Para a gente fazer uma corrente, uma onda forte! É muita ousadia e responsabilidade que eu estou falando! Porque nós vamos enfrentar os doutores, as doutoras, os vendedores de medicamentos. Porque atrás de tudo isso, a força do capital que considera o ser humano como uma mercadoria; E nessa conjuntura barra, pesada do desmonte da possibilidade de ampliação do acesso atenção a saúde integral, a rede básica com o hospital integral. Então, são provocações que eu trago aqui: Como vencer essas barreiras? Como construirmos uma ação, envolvendo lá na ponta, os fazedores de conhecimento tradicional, popular que é a ciência popular, dialogando com a chamada chancela da ciência formal?

Muito Obrigado. 